\section{A survey of dental hygienists in the United Kingdom in 2011. Part 1 - demographics and work- ing patterns as dental hygienists}

\author{
K. A. Eaton, ${ }^{1}$ M. Harris, ${ }^{2}$ M. K. Ross ${ }^{3}$ and C. Arevalo ${ }^{4}$
}

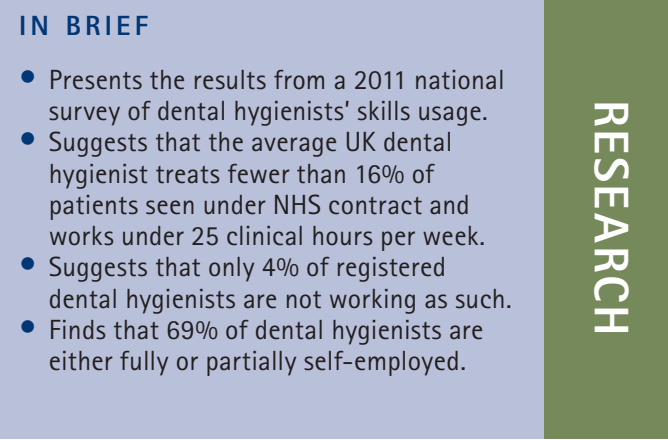

\begin{abstract}
Aims The aims of this survey were to establish the demographic profile of dental hygienists (DHs) and dental hygienist/therapists (DH/Ts) in the United Kingdom in 2011 and their patterns of practice as DHs. Methods A 10\% sample of all those registered with the General Dental Council as DHs or DH/Ts in April 2011 were sent a pre-piloted questionnaire, explanatory letter and stamped addressed envelope. The questionnaire contained a total of 100 questions, 24 of which related to demographics and working patterns. All 100 questions were solely on tasks/work performed by DH, none related to other types of work performed by DH/Ts. Three mailings were distributed between May and July 2011. The resulting data were entered into an Excel spreadsheet. Where appropriate, differences between the responses from DHs and DH/Ts were statistically tested with the chi-squared test. Results Five hundred and sixty-one DHs and DH/Ts were sent the questionnaire, by the third mailing 371 (66.1\%) had responded and returned completed questionnaires. The respondents were $288 \mathrm{DHs}, 79 \mathrm{DH} / \mathrm{Ts}$ and 4 who did not specify which category they were. The mean year of qualification of the DHs was 1990 and for the DH/Ts 2005. One hundred and twenty-four (33\%) reported that they worked full-time, 235 (63\%) parttime and the remainder that they were not working as $\mathrm{DHs}$ or $\mathrm{DH} / \mathrm{Ts}$ or had retired. The average number of clinical hours worked per week was reported as 24.6 hours for $\mathrm{DHs}$ and 25 hours for $\mathrm{DH} / \mathrm{Ts}$, but there were regional variations. For DHs the mean percentage of patients treated under NHS contract was $15.5 \%$ and for DH/Ts it was $40.2 \%$. Again there were regional variations and in Scotland these figures were 45.5\% for DHs and 70\% for DH/Ts. Two hundred and forty-eight (69\%) of all respondents were either fully or partly self-employed and 221 (62.7\%) worked in two or more locations.

Conclusions The results of this study provide a snapshot of the demographics and practice patterns of DHs and DH/Ts in the UK in the summer of 2011. They confirm the results of a survey that was conducted in England in early 2011 and of a survey that took place in Scotland in 2009.
\end{abstract}

\section{INTRODUCTION}

In the summer of 2011, the British Society of Dental Hygiene and Therapy (BSDHT), in collaboration with the Faculty of General Dental Practice (UK) (FGDP(UK)), carried out a survey of dental hygienists (DHs) in the United Kingdom. The primary aim of this survey was to establish whether or not DHs and dually qualified dental hygienist/

\footnotetext{
'Visiting Professor, University College London Eastman and King's College London Dental Institutes; ${ }^{2}$ Senior Dental Tutor, University of Portsmouth Dental Academy, William Beatty Building, Hampshire Terrace, Portsmouth, P01 20G; ${ }^{3 S}$ Senior Lecturer and Programme Director, Edinburgh Postgraduate Dental Institute, Lauriston Building (4th Floor), Lauriston Place, Edinburgh, EH3 9HA; ${ }^{2}$ Research Consultant, Centre for Flexible Learning, King's College London, 46 Aldwych, London, WC2B 4LL.

${ }^{*}$ Correspondence to: Kenneth A. Eaton Email: kenneth.a.eaton@btinternet.com
}

\section{Online article number E18}

Refereed Paper - accepted 6 July 2012

DOI: 10.1038/sj.bdj.2012.1041

${ }^{\oplus}$ British Dental Journal 2012; 213: E18 therapists (DH/Ts) were using the dental hygiene skills that they had acquired during training. Additional aims were to investigate $\mathrm{DH}$ and $\mathrm{DH} / \mathrm{T}$ working patterns and their preferences for delivery systems for continuing professional development. This paper reports the findings of the survey with regard to their demographics and working patterns.

In the United Kingdom (UK), since the publication of the Nuffield Report, ${ }^{1}$ there has been increasing emphasis on team dentistry, an increase in the range of clinical tasks which team members can perform, ${ }^{2}$ the creation of two new groups of dental care professionals (DCPs) and a requirement for all DCPs to register and complete continuing professional development throughout their practising careers. Government policy has been to develop team dentistry and increase the role of DHs and $\mathrm{DH} / \mathrm{Ts}^{3,4}$
A review of the literature, revealed only one investigation into the working patterns of DHs in the UK, ${ }^{5}$ before 1999. It was relatively limited and was a survey of DHs who qualified from one UK school between 1977 and 1986. ${ }^{5}$ It indicated that over $20 \%$ of these DHs were not working as such. Ten years later, a further survey of DHs who qualified from the same school between 1977 and 1998 was performed. ${ }^{6}$ At this time $11 \%$ were not working as a $\mathrm{DH}$. One year later, a national survey of DHs' working patterns and job satisfaction also found that $11 \%$ of DHs were not working as such, that 78\% were employed in general dental practice, $64 \%$ worked in more than one practice and most worked fewer than 30 hours per week. ${ }^{7}$ In 2002, a survey of general dental practices in the South West of England found that DHs were employed in $72 \%$ of these practices but only $20 \%$ off their work was performed under NHS 
contract. ${ }^{8}$ In contrast a survey of general dental practices in South Yorkshire found that, although many reported that they would like to employ a DH, only 33\% did. ${ }^{9}$

More recently, in 2009, a UK-wide survey of DHs and DH/Ts found that $96 \%$ of DHs and $87 \%$ of DH/Ts were employed in general dental practice and that mean working hours per week were 26 hours for DHs and 31.2 hours for DH/Ts. ${ }^{10}$ In 2010, an analysis of the dental workforce in Scotland found that $60 \%$ of practices that worked within the general dental services of the NHS employed a DH and $10 \%$ a DH/T, and that $45 \%$ of DH and 54\% of $\mathrm{DH} / \mathrm{T}$ sessions were for the delivery of care and treatment under NHS contract. ${ }^{11}$ Between December 2010 and March 2011, data on working patterns of DHs and DH/Ts in England were collected as part of a project to model the dental workforce supply. ${ }^{12}$ The findings of this survey were that $83 \%$ of DHs working time was spent in general dental practice and 6\% in specialist practice, $61 \%$ of DHs worked at more than one location and $22 \%$ of the treatment that they provided was under NHS contract. ${ }^{12}$

\section{AIMS}

Against this background, the aims of this part of the survey were to establish the demographic profile of DHs and DH/Ts in the United Kingdom in 2011 and their patterns of practice as DHs.

\section{METHODS}

This survey was conducted using a selfreported questionnaire. The questionnaire had been piloted among a random sample of 20 dental hygienists in Edinburgh and Portsmouth. After piloting some of the original questions were revised. The questionnaire ${ }^{13}$ consisted of 100 questions with sections on: practice profile, assessment skills, prevention skills, operative skills, the demography of the respondents and their continuing professional education. This paper reports on the responses to the questions on practice profile. All questions were solely on tasks/work performed by $\mathrm{DH}$, none related to other types of work performed by $\mathrm{DH} / \mathrm{Ts}$.

\section{The sample}

At the beginning of May 2011, when the questionnaire was mailed out, 5,900 were registered with the General Dental Council
(GDC) as a DH. Of these a number were also registered as dentists or dental technicians. They were excluded from the survey as it was felt that they might well be working as dentists or dental technicians and not as DHs. Of the remaining 5,610 registrants, 1330 were registered both as dental hygienists and as dental therapists (DH/Ts).

Statistical advice was that a 10\% sample of all those registered as a $\mathrm{DH}$ or $\mathrm{DH} / \mathrm{T}$ would be sufficient to achieve a error rate of 5\% and 90\% confidence level, if there was at least a $66 \%$ response rate. The GDC provided an electronic version of the register for dental care professionals, from which the names and addresses of those registered as $\mathrm{DH}$ or $\mathrm{DH} / \mathrm{T}$ were extracted. The sample was drawn by selecting every tenth name from the resulting list of 561 names and addresses.

\section{Conduct of the survey}

Before the survey, an editorial in Dental Health $^{14}$ advised dental hygienists that the survey was to take place and encouraged them to respond. At a local level, dental hygienists who attended continuing professional development courses, run by the BSDHT, were reminded of the survey and encouraged to respond.

The questionnaire was mailed to all 561 in the sample, together with a combined explanatory letter and participant information sheet, which invited them to respond, and a first class stamped addressed envelope. The letter stressed that all responses would be treated as confidential and anonymised so that no answers or information provided could be attributed to an individual. Each questionnaire carried a unique reference number for the purposes of tracking who had or had not replied. Details of the reference numbers and the names of those in the sample were stored separately from the database of the responses to the survey and were deleted when the response period for the survey had elapsed.

The first mailing was sent out at the beginning of May 2011, follow-up mailings to non-responders were sent out in June and July 2011.

\section{The questions on practice profile}

The following questions were asked:

- Are you registered as a DH or DH/T?

- Are you currently taking a career break from dental hygiene?
- Have you retired from work as a DH?

- In which year did you qualify?

- At which school did you qualify?

- What is your gender?

- In which of the following locations (regions) do you work: Scotland, Wales, Northern Ireland, South West England, London, South East England, West Midlands, East Midlands, East Anglia, North West England, North East England, Overseas?

- Do you work: full-time, or part-time or are you retired or working in another job other than as a DH?

- On average how many clinical hours do you work per week as a DH or, if you are a DH/T performing the tasks of a $\mathrm{DH}$ ?

- What type of practice/clinic do you work in: general practice, dental hygiene school, dental or other hospital, community clinic, military, body corporate, non-salaried in general practice, other (please specify)?

- What percentage of your patients is treated under NHS contract?

- What percentage of your patients is treated privately?

- If your patients are not treated under NHS contract or privately for example, you work for the military, please tick here

- Are you self-employed or salaried?

- Are you partially self-employed (for some sessions per week)?

- Do you work in more than one practice/clinic each week?

- If so in how many?

\section{Ethical approval}

The protocol for the survey, questionnaire and covering letter were sent to the South East Scotland Research Ethics Committee, who considered that it was an opinion survey seeking the respondents' views on service delivery and as such did not need NHS ethical review under the terms of the governance arrangements for research ethics committees in the United Kingdom. As no NHS funds, patients of facilities were involved, it was unnecessary to seek NHS R\&D approval for the survey.

\section{Data analysis}

Data were entered into an Excel spreadsheet. Five percent of data entries were checked for accuracy in order to assess 


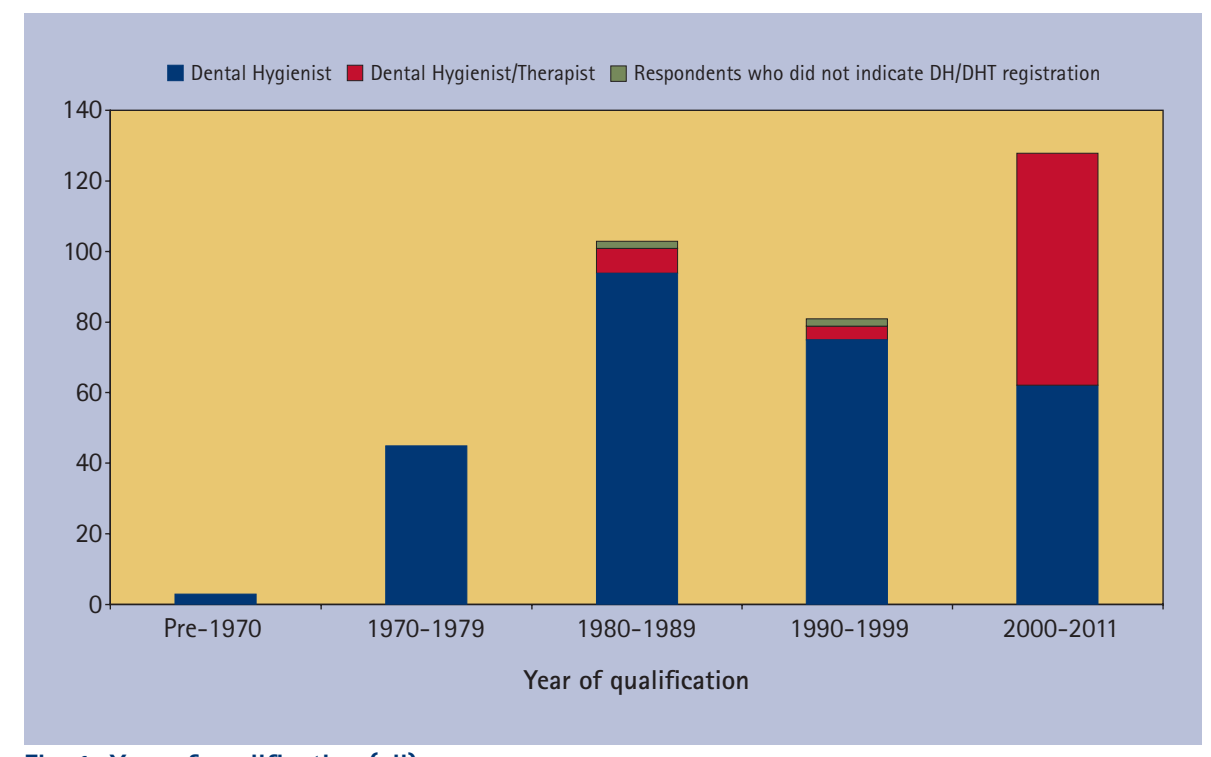

Fig. 1 Year of qualification (all)

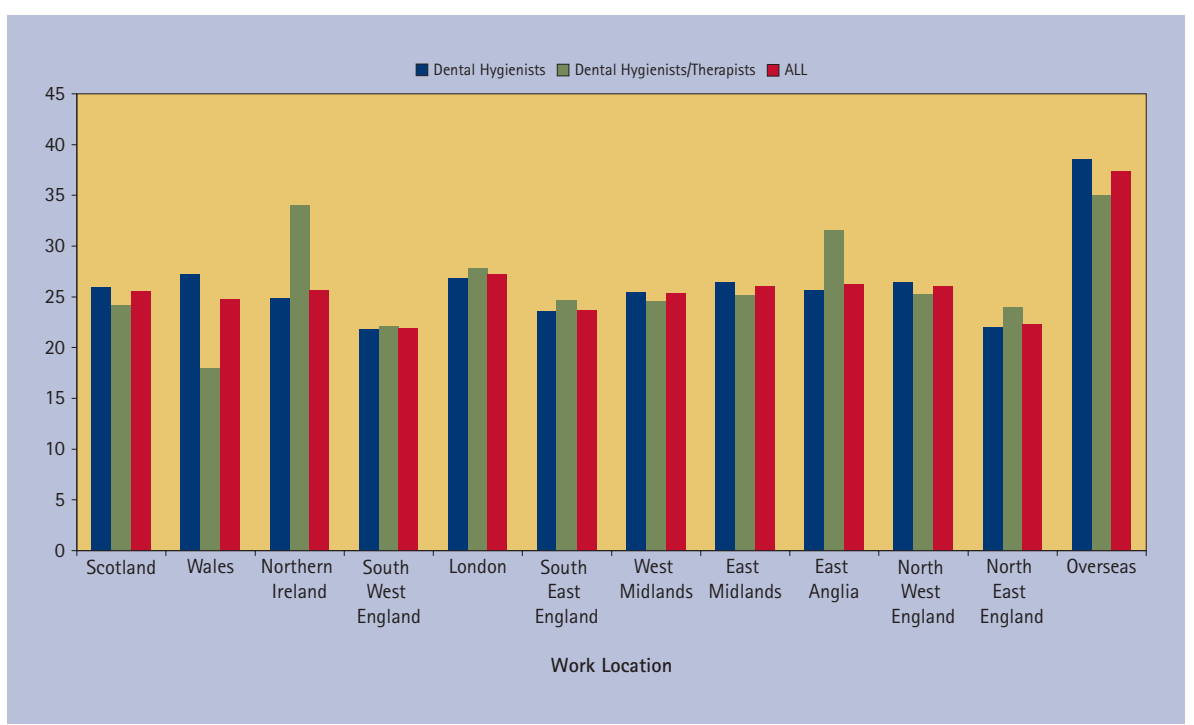

Fig. 2 Work location (all)

a percentage error for data entry. Where relevant, differences in the responses from DHs and DH/Ts were statistically tested using the chi-squared test.

\section{RESULTS}

After three mailings, 371 of the 561 in the sample (66.1\%) had responded, of whom 288 were DHs, 79 were $\mathrm{DH} / \mathrm{Ts}$ and 4 did not specify whether they were DHs or DH/Ts.

Throughout the results, when percentages are given they are based on the 371 total number and not the number who responded to each question.

The error rate for data entry in the random 5\% sample of completed questionnaires that were checked was less than $1 \%$. Twelve respondents reported that they were taking a career break and five that they had retired from work as a DH.
Year of qualification, school attended and gender

Although the overall mean year of qualification for the DHs and DH/Ts combined was 1993, there was a wide difference in the mean year of qualification of the DHs who responded to this question (1990) and that of the DH/Ts (2005). It was noticeable between 2000 and 2011 slightly more responding DH/Ts (66) than DHs (62) had qualified (Fig. 1).

A total of $359(280 \mathrm{DH}$ and $75 \mathrm{DH} / \mathrm{Ts}$ and 4 who did not specify whether they were DHs or $\mathrm{DH} / \mathrm{Ts}$ ) responded to the question on which school they had attended (Tables 1 and 2). The military schools of dental hygiene had trained 46 of the DHs, Guy's 37 and the Eastman 26. Six of the responding DHs had trained overseas (Table 1).

\begin{tabular}{|c|c|}
\hline School & No. of DHs \\
\hline Belfast & 5 \\
\hline Birmingham & 24 \\
\hline Bristol & 16 \\
\hline Cardiff & 18 \\
\hline Cork & 1 \\
\hline Dundee & 3 \\
\hline Eastman & 26 \\
\hline Edinburgh & 13 \\
\hline Guy's & 37 \\
\hline Glasgow & 11 \\
\hline King's & 15 \\
\hline Leeds & 6 \\
\hline Liverpool & 11 \\
\hline London Hospital & 1 \\
\hline Manchester & 15 \\
\hline Newcastle & 7 \\
\hline The Royal Dental & 14 \\
\hline Salford & 1 \\
\hline Sheffield & 3 \\
\hline UCL & 1 \\
\hline Military* & 46 \\
\hline Overseas** & 6 \\
\hline Did not respond & 8 \\
\hline Total & 288 \\
\hline \multicolumn{2}{|c|}{$\begin{array}{l}\text { "Army } 22, \text { DDA 6, Navy 3, Royal Air Force } 15 \\
\text { "*Barcelona 1, Bergen 1, Farmingdale (USA)1, Otago 1, Poland 1, } \\
\text { Romania } 1\end{array}$} \\
\hline
\end{tabular}

Table 2 School where dental hygienist/ therapists qualified

\begin{tabular}{l|l}
\hline School & No. of DH/Ts \\
\hline Bart's/Royal London & 6 \\
\hline Birmingham & 5 \\
\hline Bristol & 4 \\
\hline Cardiff & 2 \\
\hline Eastman & 4 \\
\hline Glasgow & 5 \\
\hline Guy's & 2 \\
\hline King's & 5 \\
\hline Leeds & 11 \\
\hline Liverpool & 9 \\
\hline Manchester & 2 \\
\hline Portsmouth & 4 \\
\hline Sheffield & 13 \\
\hline Military & 3 \\
\hline Did not respond & 4 \\
\hline Total & 79 \\
\hline
\end{tabular}


Seven people did not respond to the question on gender. Of the 364 who did, 358 were female (96.5\%) and only 6 male (1.5\%).

\section{Full-time/part-time working}

A total of 359 (277 DHs, $78 \mathrm{DH} / \mathrm{Ts}$ and 4 who did not specify) responded that they were working either full- or part-time as dental hygienists, of whom 124 (33.4\%) reported that they were working full-time and 235 (63.3\%) part-time. The other 12 (3.3\%) either did not answer this question or reported that they were either retired or working in another job.

There was an interesting difference in the percentages of DHs and DH/Ts who reported that they worked full-time. Over half of the DH/Ts (41 out of the 78 who responded to this question) reported working full-time, whereas under a third of DHs (82 out of 277) reported working full-time. A chi-squared test applied to these results found a statistically highly significant difference ( $p=0.0003)$ for this factor between the DHs and the DH/Ts.

\section{Location (region) of practice and clinical hours worked per week}

Overall 357 (277 DHs, 76 DH/Ts and 4 who did not specify) responded to these questions. The four who did not specify whether they were DHs or DH/Ts were excluded from calculations. Thus the total number of respondents to these questions was 353. The region with the most respondents was South East England (75), followed by South West England (53) (Table 3).

The overall average number of clinical hours worked per week was 24.6 hours. For DHs it was 24.4 hours and for DH/Ts it was 25.0 hours (Table 3). If the three respondents who worked overseas are excluded, the range by region for DHs was from 21.8 hours in the South West of England to 27.2 hours in London. For DH/Ts the reported range was from 18 hours in Wales to 34 hours in Northern Ireland. However, as only one DH/T from Northern Ireland and three from Wales responded to this question, there must be some doubt about the accuracy of these data and for the average clinical hours per week reported by the three $\mathrm{DH} / \mathrm{Ts}$ from East Anglia (31.5 hours) (Table 3).

\section{Type of practice}

A total of 360 responded to this question,

Table 3 Clinical hours worked per week by workplace location (region)

\begin{tabular}{|l|l|l|l|l|l|l|l|}
\hline & \multicolumn{3}{|l|}{ Average clinical hours per week } & \multicolumn{2}{l}{ Total number of respondents } \\
\hline Work location & All* & \multicolumn{2}{|l|}{$\begin{array}{l}\text { Dental } \\
\text { hygienist }\end{array}$} & $\begin{array}{l}\text { Dental } \\
\text { hygienist/ } \\
\text { therapist }\end{array}$ & All* & $\begin{array}{l}\text { Dental } \\
\text { hygienist }\end{array}$ & $\begin{array}{l}\text { Dental } \\
\text { hygienist/ } \\
\text { therapist }\end{array}$ \\
\hline Scotland & 25.5 & 25.9 & 24.1 & 21 & 16 & 5 \\
\hline Wales & 24.7 & 27.2 & 18.0 & 11 & 8 & 3 \\
\hline Northern Ireland & 25.6 & 24.8 & 34.0 & 12 & 11 & 1 \\
\hline South West England & 21.8 & 21.8 & 22.1 & 53 & 40 & 13 \\
\hline London & 27.2 & 26.8 & 27.8 & 32 & 19 & 13 \\
\hline South East England & 23.6 & 23.5 & 24.7 & 75 & 66 & 9 \\
\hline West Midlands & 25.4 & 25.4 & 24.5 & 25 & 23 & 2 \\
\hline East Midlands & 26.0 & 26.4 & 25.2 & 22 & 16 & 6 \\
\hline East Anglia & 26.4 & 25.6 & 31.5 & 15 & 13 & 2 \\
\hline North West England & 26.0 & 26.4 & 25.5 & 47 & 31 & 16 \\
\hline North East England & 22.3 & 22.0 & 24.0 & 30 & 25 & 5 \\
\hline Overseas & 37.3 & 38.5 & 35.0 & 3 & 2 & 1 \\
\hline Did not indicate region & 14.7 & 14.7 & 0 & 7 & 7 & 0 \\
\hline Total & 24.6 & 24.4 & 25.0 & 353 & 277 & 76 \\
\hline Did not respond & & & & 14 & 11 & 3 \\
\hline
\end{tabular}

*Excludes four respondents who did not indicate DH/DHT status.

\section{Table 4 Type of practice employed in}

\begin{tabular}{|l|l|l|l|l}
\hline Type & DH & DH/T & Unclear & Total \\
\hline General practice only & 158 & 43 & 3 & $204(55 \%)$ \\
\hline Combination of types & 32 & 16 & 0 & $48(13 \%)$ \\
\hline $\begin{array}{l}\text { General practice only } \\
\text { non-salaried }\end{array}$ & 74 & 11 & 0 & $85(23 \%)$ \\
\hline All others* & 13 & 9 & 0 & $22(6 \%)$ \\
\hline No response & 11 & 0 & 1 & $12(3 \%)$ \\
\hline Total & 288 & 79 & 4 & $371(100 \%)$ \\
\hline $\begin{array}{l}\text { *All others equates to employed in one of the following: dental hygiene school, dental or other hospital, community clinic, militar, body } \\
\text { corporate }\end{array}$
\end{tabular}

including three of the four respondents who did not specify whether they were DH or DH/Ts. Two hundred and four (55\%) reported that they worked in general practice only, 85 (23\%) in non-salaried general practice and $48(13 \%)$ in a combination of roles and types of practice. The remaining $22(6 \%)$ reported that they worked in one of the other practice types: a school of dental hygiene, a dental or other hospital, community clinic, for the military or body corporate (Table 4).

\section{NHS or private}

A total of 357 (277 DHs, 76 DH/Ts and 4 who did not specify) responded to this question. The four who did not specify whether they were DHs or DH/Ts were excluded from calculations. A further seven were excluded because they did not provide a location of practice or were military DHs or DH/Ts. The overall mean results were that $20.7 \%$ of patients were treated under NHS contract and 79.3\% were treated privately (Table 5). For DHs the mean was $15.5 \%$ under NHS contract and $84.5 \%$ privately. For DHs who responded the highest percentage of treatment under NHS contract was reported for Scotland (45.5\%) and the lowest from the East Midlands (2.0\%). For DH/Ts the highest percentage of treatment under NHS contract was reported from East Anglia (90\%) and the lowest from London (5.4\%) (Table 5). However, because of the very small numbers of $\mathrm{DH} / \mathrm{Ts}$ who responded from some regions, these data must be viewed with caution. 


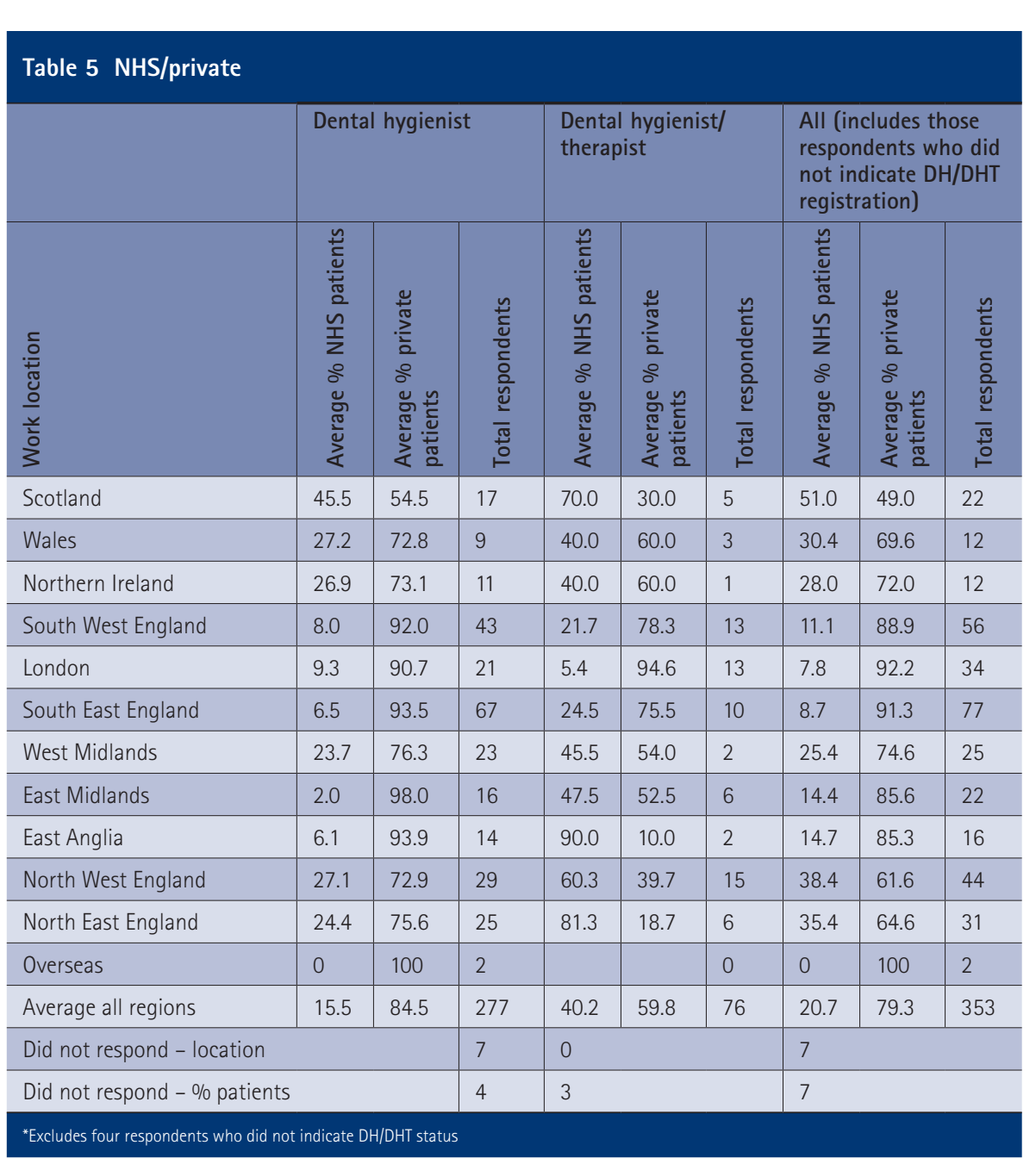

Table 6 Self-employed, partially self-employed or salaried

\begin{tabular}{|c|c|c|c|c|c|c|c|}
\hline \multirow[b]{2}{*}{ 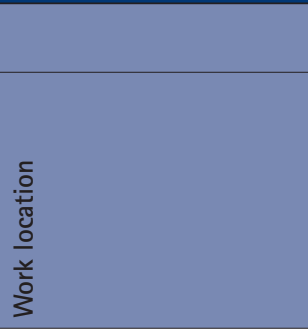 } & \multicolumn{3}{|c|}{ Dental hygienist } & \multicolumn{3}{|c|}{$\begin{array}{l}\text { Dental hygienist/ } \\
\text { therapist }\end{array}$} & \multirow[b]{2}{*}{ 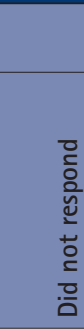 } \\
\hline & 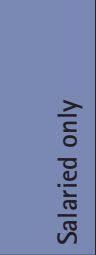 & 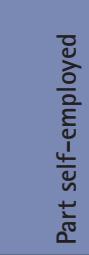 & 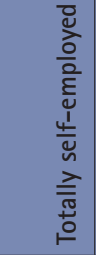 & 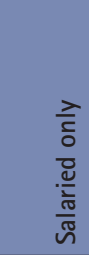 & 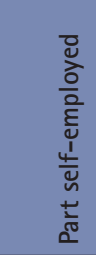 & 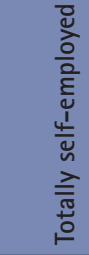 & \\
\hline Scotland & 13 & 0 & 4 & 3 & 1 & 1 & \\
\hline Wales & 4 & 1 & 4 & 0 & 1 & 2 & \\
\hline Northern Ireland & 4 & 3 & 4 & 0 & 0 & 1 & \\
\hline South West England & 18 & 8 & 17 & 5 & 2 & 6 & \\
\hline London & 3 & 3 & 15 & 2 & 2 & 9 & \\
\hline South East England & 8 & 6 & 53 & 0 & 5 & 5 & \\
\hline West Midlands & 6 & 2 & 15 & 1 & 1 & 0 & 1 \\
\hline East Midlands & 5 & 2 & 9 & 4 & 2 & 1 & \\
\hline East Anglia & 4 & 2 & 8 & 1 & 1 & 0 & \\
\hline North West England & 11 & 2 & 18 & 5 & 3 & 8 & \\
\hline North East England & 10 & 3 & 13 & 2 & 2 & 2 & \\
\hline Overseas & 1 & 1 & 0 & 1 & 0 & 0 & \\
\hline Total & 87 & 33 & 160 & 24 & 20 & 35 & 1 \\
\hline Did not respond - location & & & 7 & & & 0 & \\
\hline
\end{tabular}

\section{Self employed/salaried}

When the four respondents, who did not specify whether they were DHs or DH/Ts were excluded, a total of 359 responded to this question. One hundred and ninety-five (160 DHs and $35 \mathrm{DH} / \mathrm{Ts}$ ) reported that they were totally self-employed, 53 (33 DHs and $20 \mathrm{DH} / \mathrm{Ts}$ ) that they were partially selfemployed and 111 (87 DHs and $24 \mathrm{DH} / \mathrm{Ts}$ ) that they were salaried only (Table 6).

\section{Number of practices/clinics worked in}

A total of 353, who were working as DHs responded to this question, of whom 133 (35.8\%) reported that they worked in only one practice/clinic and 221 (62.7\%) that they worked in more than one practice. Six responses were unclear and 11 did not respond to this question. The majority (211 DHs + $49 \mathrm{DH} / \mathrm{Ts}-73.5 \%)$ who responded reported that they worked in either one or two practices/clinics during a week. Sixty-seven DHs and 29 DH/Ts responded that they worked in more than two practices during the week (Table 7). When a chi-squared test was applied there was a statistically significant difference $(p=0.031)$ in the proportion of DHs and $\mathrm{DH} /$ Ts working in more than two practices per week with a higher proportion of DHs than $\mathrm{DH} / \mathrm{Ts}$ following this working pattern.

\section{DISCUSSION}

As it is virtually impossible to obtain a $100 \%$ response rate, there are always some doubts about the validity of results obtained from postal questionnaire surveys. The $66.1 \%$ response rate can be viewed as satisfactory as advice was that this level of response from a 10\% sample should have been sufficient for no more than 5\% error at a 90\% confidence level. It should be remembered that although the overall response rate was $66.1 \%$, the response rate and useable responses to individual questions were slightly lower. However, as there were at least 353 useable responses (out of a possible 371) to each question the potential error should still be small when the data are considered at a national level. The response rates to the recent surveys of DHs and $\mathrm{DH} / \mathrm{Ts}$ in the $\mathrm{UK}^{10}$ and England ${ }^{12}$ were $65 \%{ }^{10}$ and 56\% for $\mathrm{DH} / \mathrm{Ts}^{12}$ and $48 \%$ for $\mathrm{DHs}^{12}$ respectively. However, in the current survey when subanalyses at regional level were performed 
the numbers were sometimes very small for example, responses from five or fewer DH/Ts in East Anglia, Northern Ireland, Scotland, Wales and the West Midlands. Therefore the potential for greater error has to be accepted in the sub-analyses.

The demographic results were unsurprising. It was reassuring that the demographic profile of respondents matched that of the DHs and DH/Ts on GDC's register in that just under 2\% were male, the mean year of qualification for DHs was 1990 and 2005 for DH/Ts and more DH/Ts than DHs had qualified since 2000 . These findings were also reflected by respondents in the recent dental workforce supply survey in England, in that only $28 \%$ of $\mathrm{DH}$ respondents in this survey were 35 years or younger as opposed to just over $50 \%$ of DH/Ts. ${ }^{12}$ It was interesting to see that in spite of closures of the Royal Navy and Royal Air Force schools of dental hygiene, the high numbers of DHs that qualified from military schools of dental hygiene in the past were reflected by the number of DH respondents who had trained at military schools. This was not the case for DH/Ts, few of whom have been trained by the military.

Previous studies have reported that DH frequently work part-time. ${ }^{7,10}$ In the current study, the average clinical hours worked per week by DH were 24.4 hours and 25 hours by DH/Ts. The 2009 national study of DHs and $\mathrm{DH} / \mathrm{Ts}^{10}$ reported that the mean working hours per week for DHs was 26 and 31.2 for DH/Ts. However, some of these hours may well not have been clinical and in the case of $\mathrm{DH} / \mathrm{Ts}$ not spent providing dental hygiene care and treatment. As mentioned previously in the results section, the finding of apparent wide variation between regions for clinical hours worked by DH/Ts (18-34 hours for those in the UK), as opposed to 21.8-27.2 for DHs, may well have resulted from the small numbers of $\mathrm{DH} / \mathrm{Ts}$ responding from some regions. Although, part-time working has been common among DHs for many years. There may be a smaller percentage of DHs and DH/Ts who are either taking career breaks or are not working as DHs or DH/Ts. In a 1989 survey, 23\% of the DHs who responded were either taking career breaks or not working as DHs. ${ }^{5}$ A survey published in $2000^{6}$ indicated that $11 \%$ of respondents were in these two categories. In the current survey, just over 96\%

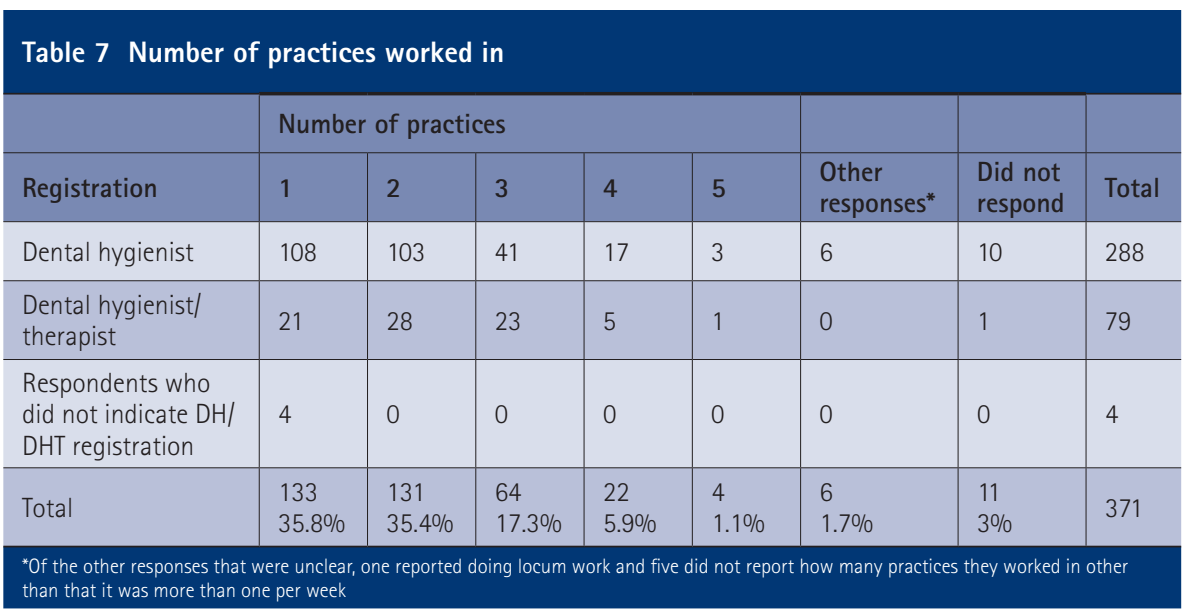

reported that they were working as either $\mathrm{DH}$ or DH/Ts of whom a third said they were working full-time and two thirds parttime. It was noticeable that over $50 \%$ of $\mathrm{DH} / \mathrm{Ts}$ reported working full-time, whereas the percentage for DHs was only 30\%. In part this difference may be due to the fact that the $\mathrm{DH} / \mathrm{Ts}$ tended to be younger.

As in previous studies, ${ }^{6,10-12}$ the current study indicated that the majority of both DHs and DH/Ts worked in general dental practice. Because different studies have described practice types slightly differently, it is difficult to make direct comparisons. In the current study the $78 \%$ of respondents who reported that they worked in 'general practice only' or 'non-salaried general practice only' clearly worked in general practice. However, some of the further 13\% who reported working in a 'combination of types' undoubtedly also worked in general practice.

The finding that overall the DHs and $\mathrm{DH} / \mathrm{Ts}$ who responded on average treated only $20.7 \%$ of patients under NHS contract was also consistent with the results of previous studies. ${ }^{8,10,12}$ As were the findings that $\mathrm{DH}$ on average treated less than $20 \%$ of patients under NHS contract and $\mathrm{DH} / \mathrm{Ts}$ around $40 \%$. It was noticeable that in Scotland, where the payment system within the NHS did not change in 2006, the percentage of patients seen under NHS contract by both DHs (45.5\%) and DH/Ts (70\%) was higher. These percentages were very similar to those found in 2010 during the Scottish Strategic Review that is, $44.9 \%$ for DHs and $74.0 \%$ for DH/Ts. ${ }^{11}$

Historically, dental therapists (DTs) worked in salaried posts and many DHs were fully or partially self-employed. Since the introduction of combined DH and DT training and the opportunity for DTs to work in general practice, this pattern appears to have changed. In the current survey, 69\% (248) DHs and DH/Ts reported working either fully or partially as selfemployed and there was little difference between the DHs and the DH/Ts. It also seems to be a very common characteristic of both DHs and DH/Ts to work in more than one location. In the current study, $62.4 \%$ of respondents worked in two or more locations. In the Modelling the dental workforce supply in England survey, which was conducted three months before the current study, $61 \%$ of DH and 59\% of $\mathrm{DH} / \mathrm{Ts}$ were found to work in more than one location. ${ }^{12}$

\section{CONCLUSIONS}

The results of this study provide a snapshot of the demographics and practice patterns of DHs and DH/Ts in the UK in the summer of 2011. They confirm the results of a survey that was conducted in England in early 2011 and of a survey that took place in Scotland in 2009.

The authors wish to thank: Oral B for sponsoring the costs of this survey; the BSDHT and the $F G D P(U K)$ for their collaboration and promotion of the survey; Sue Adams and her team from the Adams Partnership for distributing the questionnaire and data input to the Excel spreadsheet; the General Dental Council for making an electronic version of the dental care professionals register available to the principal investigator; all the DHs and $D H / T s$ who responded to the survey.

1. The Nuffield Foundation. Education and training of personnel auxiliary to dentistry. London: The Nuffield Foundation, 1993.

2. General Dental Council. Scope of practice. London: GDC, 2009.

3. Department of Health. Modernising NHS dentistry implementing the NHS plan. London: DH, 2000.

4. Scottish Executive Health Department. An action plan for improving oral health and modernising NHS dental services in Scotland. Edinburgh: Scottish Executive, 2005.

5. Hillam D G. Career patterns of dental hygienists 
qualifying from the Liverpool Dental Hospital School of Dental Hygiene. Br Dent J 1989; 166: 310-311.

6. Hillam D G. A survey of hygienists qualifying from the Liverpool School of Dental Hygiene 1997-1998. Br Dent J 2000; 188: 150-153.

7. Gibbons D E, Corrigan M, Newton J T. A national survey of dental hygienists: working patterns and job satisfaction. Br Dent J 2001; 190: 207-210.

8. Sprod A, Boyles J. The workforce of professionals complementary to dentistry in the general dental services: a survey of general dental practices in the South West. Br Dent J 2003: 194: 389-397.
9. Jackson R J, Baird W O, Worthington LS, Robinson $P G$. A survey to investigate shortfalls in the dental care professional (DCP) workforce in South Yorkshire in 2004. Prim Dent Care 2007; 14: 129-135.

10. Turner S, Ross M K, Ibbetson R J. Dental hygienists and therapists: how much professional autonomy do they have? How much do they want? Results from a UK survey. Br Dent J 2011; 210: E16.

11. Scottish Government. An analysis of the dental workforce in Scotland: a strategic review 2010. Edinburgh: Scottish Executive, 2011.

12. Robinson P G, Patrick A, Newton T. Modelling the dental workforce supply in England. Sheffield: The University of Sheffield, 2011. Online report available at www.mee.nhs.uk/PDF/Dental_Workforce_Supply. pdf (accessed September 2012).

13. British Society of Dental Hygiene and Therapy/ Faculty of General Dental Practice (UK).

Questionnaire on dental hygienist skills usage London: BSDHT/FGDP(UK), 2011. Online questionnaire available at http://www.bsdht.org.uk/res/ BSDHTFGDP\%200UESTIONNAIRE\%20FINAL\%20 VERSION\%20@\%204\%20May\%202011.pdf (accessed September 2012).

14. Lewis H. Editorial. Dental Health 2011; 50: 4 